\title{
Practical Thermal Resistance and Ice Requirement Calculations for Insulating Packages
}

\author{
By Gary Burgess*
}

Several styles of insulating packages were studied, ranging in size from 0.5 to 5 cubic feet and varying in construction from the ordinary expanded polystyrene cooler to various liner-in-box arrangements with and without aluminium foil surfaces. Ice-melt tests were conducted to measure package insulating ability and the results were used to determine the thermal resistance (R-value). The R-value was then related to details connected with package construction including wall thickness, number of layers and number of foil surfaces through a simple equation so that it can be estimated for any construction. The system R-value can then be used to estimate refrigerant requirements and temperature holding times for known shipping environments. Examples are included. Copyright (C) 1999 John Wiley \& Sons, Ltd.

Received 18 October 1998; Accepted 13 January 1999

KEY WORDS: insulating package; thermal resistance; $R$-value; temperature holding time; ice requirements

\section{INTRODUCTION}

The most common container in use today for shipping temperature - sensitive products is the moulded polystyrene container, or 'cooler'. Over the past few years, composites like bag-in-box and liner-in-box arrangements, have been developed which compete with the cooler in performance. This layered approach traps a thin blanket of air between the liner and box which adds a significant resistance to heat penetration. This is the same principle behind double and triple pane windows and wearing layered clothes in the winter. ${ }^{1-3}$ If aluminium foil surfaces are added to the liner/ bag/box faces, this further increases resistance, substantially in most cases, for reasons explained in the Appendix.

One objective of this paper was to quantify the insulating ability of a package by specifying a means for calculating its thermal resistance or ' $R$ value', which is a common measure of resistance to heat flow used in the construction industry in the United States. A second objective was to show how to use this $R$-value to estimate ice requirements and temperature holding times for products packed in ice in these containers. The third and final objective was to promote the method used here as a simple do-it-yourself procedure that works well for all heat transfer studies involving insulating packages.

The method is based on the principle that $1 \mathrm{lb}$ $(454 \mathrm{~g})$ of regular ice at its melting point of $32^{\circ} \mathrm{F}$ must absorb $144 \mathrm{Btu}(36.3 \mathrm{kcal}$ or $151.9 \mathrm{~kJ})$ of heat to melt. By placing a known quantity of ice inside the package and storing it in a constant temperature environment above $32^{\circ} \mathrm{F}$, the measured rate at which the ice melts gives a direct indication of the rate of heat flow into the package.

\footnotetext{
* Correspondence to: G. Burgess, School of Packaging, Michigan State University, East Lansing, MI 48824-1223, USA.
} 


\section{and Science}

\section{EXPERIMENTAL PROCEDURE}

The following very simple, inexpensive and effective way to measure the insulating ability of a package was used to test a number of different bag/liner-in-box configurations with and without aluminium foil surfaces. This test closely resembles the situation in which it would actually be used and is similar to the one recommended in ASTM D3103: Standard Test Method for Thermal Insulation Quality of Packages, ${ }^{4}$ but with a different objective. No temperature sensors or special equipment are required.

The 'ice-melt test' begins by placing a quantity of regular cubed or crushed store ice in a nonmetallic bucket inside the package, loosely closing the package, and letting it sit at room temperature. The amount of ice should be chosen to utilize at least half of the available volume. The ice is allowed to melt for several hours, after which the bucket is removed and the water drained out and discarded. This is a preconditioning procedure intended to ensure that the ice is uniformly at its melting temperature, $32^{\circ} \mathrm{F}$, before the actual test begins and not at the freezer temperature (about $\left.0^{\circ} \mathrm{F}\right)$ in the store where the ice was bought. This maintains a constant temperature difference across the package wall for the next part of the test. The ice should be uniformly wet over its entire surface at the conclusion of this stage. Metallic buckets should not be used because they can interfere with the calculation of the package $R$-value by providing a reflective surface not associated with the package itself.

The bucket is then placed back inside the package near the centre and the package is sealed with tape to make it relatively air tight. Sealing is an important step: stray air currents can flow in and out through the smallest of openings and can carry enough heat with them to render even the best insulator ineffective. The day and time are noted and the package is immediately placed in a draught free constant temperature environment indoors, above $32^{\circ} \mathrm{F}$, on a shelf or other surface off the floor. Room temperature is sufficient. The package is allowed to sit in this environment for at least one day and possibly two or three depending on the package. The aim is to get most, but not all, of the ice to melt. A good way to do this, without having to open the package and periodically check, is simply to bump it and listen for the rattle of the ice. It is obvious when there is little ice left. If all the ice has melted, the experiment must be repeated from the beginning.

At the end of this period of time, the day and time are noted, the box is opened, the bucket removed and the water again drained out. This time however, the water is collected and weighed. Since it takes $144 \mathrm{Btu}$ of heat to melt $1 \mathrm{lb}$ of ice (the latent heat), the heat transfer rate in $\mathrm{Btu} / \mathrm{h}$ into the package is the melt rate multiplied by the latent heat. This can then be turned into a 'system $R$ value $^{1-3}$ using

system $R$-value $=\frac{(\text { box area })(\text { temperature difference })}{(\text { melt rate })(\text { latent heat })}$

The $R$-value depends mainly on the wall construction, not the size of the package, and is the reciprocal of the effective coefficient of heat transfer. The 'box area' term is the inside surface area of the package, since this is what ultimately limits heat transfer to the product and should be in square feet if a comparison with US industrypublished $R$-values for building materials is to be made. The temperature difference term is the temperature difference between the outside air and the ice. If the constant temperature environment used is room temperature of say $72^{\circ} \mathrm{F}$, then the temperature difference is constant at $72^{\circ} \mathrm{F}$ $-32^{\circ} \mathrm{F}=40^{\circ} \mathrm{F}$ because throughout the time the ice is melting, it stays at $32^{\circ} \mathrm{F}$ as long as there is any ice still left. The 'melt rate' term is the rate at which ice melts during the experiment and is equal to the weight of the water (melted ice) collected divided by the exposure time. If $10 \mathrm{lb}$ of water is drained from the bucket after $50 \mathrm{~h}$ of letting it sit following preconditioning, then the melt rate is $10 / 50=$ $0.2 \mathrm{lb} / \mathrm{h}$. So for a package having inside dimensions of $1 \mathrm{ft} \times 1 \mathrm{ft} \times 1 \mathrm{ft}\left(\right.$ surface area $\left.6 \mathrm{ft}^{2}\right)$ in which $10 \mathrm{lb}$ of ice melted in $50 \mathrm{~h}$ when stored at $72^{\circ} \mathrm{F}$, the system $R$-value would be

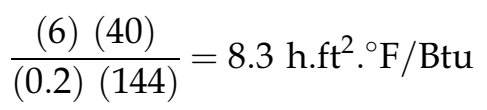

The same experiment can be done with dry ice (solid $\mathrm{CO}_{2}$ ). Since dry ice goes directly from a solid to a gas, the 'melt rate' should be calculated as the difference between the starting and ending 


\section{and Science}

weights of the block of dry ice used, divided by the exposure time. The temperature difference must be based on an ice temperature of $-108.4^{\circ} \mathrm{F}$ instead of $32^{\circ} \mathrm{F}$, and a latent heat of $240 \mathrm{Btu} / \mathrm{lb}$ instead of 144. Whichever method is used, the $R$-value should be the same. Dry ice was not used to obtain $R$-values in this study because using it represented an unnecessary complication in a procedure which was meant to be simple. Ice requirements and temperature holding times for actual products like frozen fish and chicken packed in dry ice were later calculated and then verified using $R$-value predictions based on melt tests done with regular ice.

The $R$-value obtained here is a reciprocal coefficient of heat transfer and is very similar, but not identical, to conventional $R$-values used to rate building insulation in the US. Conventional $R$ values represent an outside air to inside air resistance, not, as here, outside air to product. ${ }^{1,3}$ A nominal air-to-air $R$-value for $31 / 2$ in thick fibreglass wall insulation is ' $R-11 \mathrm{~h} . \mathrm{ft}^{2} .{ }^{\circ} \mathrm{F} / \mathrm{Btu}^{\prime}$, which translates into an air-to product $R$-value of about 12.5 (add 1.5) as will be shown later. Useful conversions between English and SI units are:

\section{latent heat: $1 \mathrm{Btu} / \mathrm{lb}=2.33 \mathrm{~kJ} / \mathrm{kg}$}

$R$-value unit: $1 \mathrm{~h} . \mathrm{ft}^{2} .{ }^{\circ} \mathrm{F} / \mathrm{Btu}=0.176 \mathrm{~m}^{2} .{ }^{\circ} \mathrm{C} /$ watt

\section{TEST RESULTS}

Various box sizes and wall constructions were tested. The sizes ranged from about 0.5 to 5 cubic feet in volume and the wall constructions included a corrugated box by itself, the same box with one or two foam liners, with and without aluminium foil surfaces, and thick walled moulded polyurethane and polystyrene coolers. Only two different storage temperatures were used in a test, but not in all instances: $72^{\circ} \mathrm{F}$ and $104^{\circ} \mathrm{F}$. Melt rates were collected over a number of months as a result of performance tests done on about 10 industry products and compiled into one data file numbering about 50 test results. At least three different available sizes of the following packages were tested at these two temperatures. Where used, 'box' refers to a single-wall C-flute corrugated box and 'liner' refers to either a foam or bubble-wrap insert 0.125 to 0.25 inches thick.
1. Expanded polystyrene cooler.

2. Urethane foam cooler in a box.

3. Box.

4. Box with aluminiumized interior.

5. Box with plain poly liner.

6. Box with aluminiumized liner (one face).

7. Box with aluminiumized liner (both faces).

8. Aluminiumized box with aluminiumized liners.

\section{System $R$-value}

The observed melt rates were converted into system $R$-values using equation 1 and the $R$-values were fitted to a formula (equation (2a)) which takes into account the separate effects of the three heat transfer processes taking place simultaneously: conduction, convection, and radiation. The contribution of conduction to the overall $R$-value depends only on the total wall thickness: box plus liner(s). Convection refers to heat transfer between air and a surface ${ }^{2}$ and so the contribution of convection to the overall $R$-value depends on the total number of surfaces in contact with air. This is the 'layered effect'. For a plain corrugated box or EPS cooler, there are three surfaces: the outside and inside of the box, and the product. For a box with a single non-foil liner, there are five: add two more for each surface of the liner. Radiation refers to the absorption and emission of infra-red heat energy and can be a very significant factor, especially where reflective surfaces like aluminium foil are used. This principle is used in the thermos bottle. Radiation like convection, is primarily a surface phenomenon and so the number of surfaces becomes important. ${ }^{1}$ Unlike convection however, the type of surface matters most. Aluminium surfaces present both convection and radiation barriers, whereas plain surfaces present only a convection barrier.

In English units, the equation which best fit the observed results using linear regression is

$$
R \text {-value }=3.9 t h+1.5 n p+3.2 n f( \pm 20 \% \text { accuracy })
$$

where th represents the average wall thickness in inches (box plus liners), $n p$ is the number of plain surfaces, and $n f$ is the number of aluminium foil surfaces. In SI units, 


\section{and Science}

$$
R \text {-value }=0.27 t h+0.26 n p+0.56 n f
$$

where th is in cm, $R$-value is $\mathrm{m}^{2} .{ }^{\circ} \mathrm{C} / \mathrm{watt}$, and the accuracy is the same.

Surfaces should be considered plain unless they are covered with aluminium foil: examples are corrugated and foam. The three terms in the $R$ value equation relate to conduction, convection and radiation, respectively. The ' $20 \%$ accuracy' term bounds the largest difference between the observed (equation (1)) and calculated (equation (2a)) $R$-values for all the data. The correlation coefficient for the fit to 50 test results was $R^{2}=0.96$. The theoretical justification for the chosen form of equation (2a) is given in the Appendix along with some elaboration on the principles and assumptions involved.

As an example, consider an ordinary foam cooler with 11 / 2 inch thick walls. The number of plain surfaces is three: the outside of the cooler, the inside of the cooler and the product. The number of foil surfaces is zero. The system $R$-value according to equation $(2 \mathrm{a})$ is $(3.9 \times 1.5)+(1.5 \times$ $3)+(0)=5.85+4.5+0=10.35$. A little over half of the insulating ability is due to wall thickness, and the rest is due to contact resistance with air. In comparison, the $R$-value for a $\frac{1}{8}$ inch thick corrugated box alone is only 5 . This time a much smaller portion $(10 \%)$ is due to wall thickness. Laminating an aluminium foil layer onto the inside of the corrugated box improves its insulating ability substantially: now the system $R$-value is $(3.9 \times 0.125)+(1.5 \times 2)+(3.2 \times 1)=6.7$ instead of 5 . The increase is due entirely to the radiation barrier provided by the foil.

Based on the experimental results embodied in equation (2a), the following generalizations regarding wall construction can be made:

(a) For single-wall containers with plain surfaces, $n p=3$ and the contributions of wall thickness and contact resistance are equal when $3.9 \times t h=1.5 \times 3$, which gives a thickness of a little over an inch.

(b) An aluminium foil surface is $3.2 / 1.5$, or about twice as effective as a plain surface. This is due to the fact that a foil surface acts as both a plain surface for convection and a reflective surface for infra-red radiation.

(c) Placement of the foil inside or outside the box and/or liner has no effect on $R$-value. In theory, foil should have a slightly greater effect when placed on the outside, facing the hottest environment, but no such effect was observed in the ice-melt tests.

(d) The inclusion of inside air-to-product contact resistance in the definition of system $R$ value adds one more plain surface to $n p$ and so the relation to the conventional air-to-air $R$-value is: conventional $R$-value $+1.5=$ system $R$-value.

\section{Ice requirements}

One use of the $R$-value in equations $(2 a, b)$ is to compare different wall constructions as in the examples above. Another is to estimate how much ice would be needed inside a package to keep the product cool under constant temperature trip conditions. This estimate comes from a simple rearrangement of equation (1),

$$
\mathrm{lb} \text { ice }=\frac{\left.(\text { box area }) \begin{array}{c}
\text { (temperature } \\
\text { difference })
\end{array} \text { exposed }\right)}{(R \text {-value })(\text { latent heat })}
$$

The terms in equation (3) are the same as before with 'hours exposed' corresponding to the trip duration. A cooler with $1 \frac{1}{2}$ inch walls and internal dimensions of $1 \mathrm{ft} \times 1 \mathrm{ft} \times 1 \mathrm{ft}(R$-value $=10.35)$ in $100^{\circ} \mathrm{F}$ storage for $48 \mathrm{~h}$ would require

$$
\frac{(6)(100-32)(48)}{(10.35)(144)}=13 \mathrm{lb}
$$

of regular ice. After $48 \mathrm{~h}$, all the ice would be melted and the product temperature would gradually rise. If there is any amount of water in the product itself, as with most foods, and the product is frozen prior to packing, then this contributes to the ice requirement. So $10 \mathrm{lb}$ of frozen fish (typically $80 \%$ water) would contribute $8 \mathrm{lb}$ of ice to the $13 \mathrm{lb}$ required in the example above, leaving $5 \mathrm{lb}$ to be added externally. At the end of the $48 \mathrm{~h}$, the ice would be melted and the fish thawed.

If the cooler is exposed for $48 \mathrm{~h}$ to cyclic conditions roughly simulating day/night temperatures inside a truck, say $100^{\circ} \mathrm{F}$ for $14 \mathrm{~h}$ and then $60^{\circ} \mathrm{F}$ for $10 \mathrm{~h}$ on a daily basis, then the amount of ice required would be $6 \times 58 \times 14 / 10.35 \times$ $144=3.3 \mathrm{lb}$ for each daytime period, and $6 \times 28 \times 10 / 10.35 \times 144=1.1 \mathrm{lb}$ for each nighttime period, to give a total of $8.8 \mathrm{lb}$ for two full days, less any contributed by the product. 


\section{and Science}

Although dry ice has a greater latent heat of sublimation, at $240 \mathrm{Btu} / \mathrm{lb}$, than the $144 \mathrm{Btu} / \mathrm{lb}$ of regular ice, its temperature of sublimation, $-108.4^{\circ} \mathrm{F}$ is much lower than the melting point of ice. This increases the temperature difference between the inside and outside of the package from $(T-32)^{\circ} \mathrm{F}$ to $(T+108.4)^{\circ} \mathrm{F}$ in equation (3). So the quantity of dry ice needed can be greater, in some circumstances, than that of regular ice.

Equation (3) can also be used for the various gel packs on the market. These are usually water based liquids sealed in flexible or rigid plastic containers. Most are fairly similar to regular ice in that they freeze/melt at around $32^{\circ} \mathrm{F}$ and require about 144 Btu of heat to melt $1 \mathrm{lb}$ of the substance. Various chemicals added to water change both the melting point (antifreeze effect) and the latent heat somewhat and so, depending on the type and amount of chemicals, both could be affected. The only difference in equation 3 when using these gel packs is that the latent heat for this substance should be used. This information can usually be obtained from the manufacturer. Melting point should also be considered because the product will be surrounded by ice at this temperature throughout the melting process.

Ice requirements can also be stated in terms of volume instead of weight. First figure the weight required and then use the following densities for a solid block. For reference purposes,

regular ice: $1 \mathrm{lb}=27.7 \mathrm{in}^{3}$

dry ice: $1 \mathrm{lb}=19.5 \mathrm{in}^{3}$

gel packs: most similar to regular ice

Although equation (3) was developed for constant temperature exposure conditions, it may be used for variable conditions by applying it repeatedly to blocks of time during which the temperature does (or is assumed to) remain constant.

\section{Warm-up times}

It is often the case that temperature-sensitive products are precooled below $32^{\circ} \mathrm{F}$ before packing in regular ice, and can tolerate temperatures well above $32^{\circ} \mathrm{F}$ during shipment. In this situation, 'safe' times are longer than the above melt calculations imply because the product will spend some time before and after the ice melts warming up. The melt calculations are concerned with only the second step, which almost always happens to be the longest by a sizeable margin. A representative comparison might be 48 hours for melting versus $8 \mathrm{~h}$ for warming up. Melting time estimates are simple because the temperatures inside and outside the package are constant for the whole time. Warm-up time estimates are much more difficult, in part because the inside temperature keeps changing, and because now, thermodynamic information about the product must be known: in particular, density, heat capacity and thermal conductivity, all of which are functions of moisture content. The size and shape of the product also play a role in controlling the rate of heat absorption and in determining the temperature profile within the product during warm-up.

Because of the difficulty in obtaining reliable thermodynamic information, the complexity of the calculations involved, and the value of the end result given that the melt time is the most significant part, estimating warm-up times becomes impractical, especially since the controlling force, the outdoor temperature during actual shipments, will never be known exactly anyway. Uncertainty in shipping temperatures is a fact of life and affects melt rate calculations also, but in this case, the effort spent on calculation is consistent with the level of certainty. It might be best to consider the contribution of warm-up times to the overall 'safe trip time' to be a safety factor over and above the main contribution, the melt time.

\section{APPENDIX-THEORY}

It is shown in basic heat transfer texts ${ }^{1,2}$ that the steady-state rate of heat flow through a wall by conduction is

$$
\frac{\mathrm{Btu}}{\mathrm{h}}=\frac{(k) \text { (area) (temperature difference) }}{\text { th }}
$$

where th is the thickness of the wall, temperature difference is the difference in surface temperatures between the two sides, 'area' is the surface area of one side, and $k$ is the thermal conductivity of the wall material. The denser the material, the higher the conductivity, meaning that Btu's find it easier to penetrate. Packaging materials like corrugated board, foam and fibrous wadding entrap air, making them less dense and less conductive, and 


\section{and Science}

have similar conductivities: $0.035 \mathrm{Btu} / \mathrm{h} . \mathrm{ft} .^{\circ} \mathrm{F}$ for corrugated board, 0.012 for low-density foam and 0.02 for 'felt hair' and 'glass wool' wadding. ${ }^{1,2}$ The average value for these is 0.022 . Moisture content can change the conductivity of these materials by as much as $\pm 15 \%$ in going from $50 \%$ r.h. to extremes in r.h. ${ }^{3}$

The steady state rate of heat exchange between air and one side of the wall (convection) follows a similar law, ${ }^{1,2}$

$$
\frac{\mathrm{Btu}}{\mathrm{h}}=(c) \text { (area) (temperature difference) }
$$

where the temperature difference is now between the air and the wall surface, and $c$ is the "convection heat transfer coefficient'. The term 'convection' refers to heat that is absorbed by the air through direct contact with the surface and swept away by air currents created by heated air rising. Air currents that exist within and around packages are small and therefore so is $c$. For most surfaces the size and shape of those encountered in packaging applications, $c$ is about $0.8 \mathrm{Btu} /$ h. $\mathrm{ft}^{2}{ }^{\circ}{ }^{\mathrm{F}}{ }^{1}$

Whenever heat flows from air onto one side and then through a wall and out to air again on the other side, possibly repeating this several times, as in the case of layered materials used in some insulating packages, conduction and convection takes place many times and it becomes convenient to combine the effects by writing

$$
\frac{\mathrm{Btu}}{\mathrm{h}}=\frac{\text { (area) (temperature difference) }}{R}
$$

where the temperature difference is now between the source of heat (the outside air in the case of an insulating package) and the product, and $R$ is the so-called $R$-value, or combined resistance to heat penetration. ${ }^{1-3}$ From equation $6, R$ is the time it takes in hours for $1 \mathrm{Btu}$ to flow through an area of $1 \mathrm{ft}^{2}$ as a result of a $1^{\circ} \mathrm{F}$ temperature difference. Likewise, from equations 4 and $5, t h / k$ and $1 / c$ are the times required by conduction and convection alone. Since times are additive, these 'resistances in series' combine according to

$$
R=\frac{t h}{k}+\frac{1}{c}
$$

for one conduction and one convection process. For layered materials with airspaces in between, add as many $t h / k$ terms as there are layers, and as many $1 / c$ terms as there are surfaces. Doing so with $k=0.022$ and $c=0.8$, and replacing th with th/12 in equation 7 so that the proper units for $R$ are obtained when the thickness is in inches gives

$$
R=3.79 \text { th }+1.25 n p
$$

where th is now the combined thickness in inches of all layers, which are assumed to have similar $k^{\prime} s$, and $n p$ is the number of surfaces. If all surfaces are plain, then $n p$ is twice the number of layers, plus one for the product. Equation (8) is the expected result for the first two terms in equation (2a).

Aluminiumized surfaces play a double role: they transfer heat to air by convection and reflect incoming infra-red radiation, making them a much better barrier to heat than a plain surface alone. Aluminium foil reflects $95 \%$ of incoming radiation as long as it is at least 99\% pure. When combined with convection, the effects are additive and foil provides approximately twice as much resistance as a plain surface. This should add another term into equation $(8)$ equal to $(2 \times 1.25)$ per foil surface or $2.5 n f$ to account for all foil surfaces. With this addition, equation (8) becomes the theoretical version of equation (2a). Equations $(2 \mathrm{a}, \mathrm{b})$ are more reliable, however, because the numbers were chosen to fit experimental data best.

\section{REFERENCES}

1. Holman, J. P. Heat Transfer, 6th edition, McGraw-Hill Book Co. (1986).

2. Krieth, F. Principles of Heat Transfer, 3rd edition, Intext Press (1973).

3. ASHRAE Handbook Fundamentals, American Society of Heating, Refrigeration, and Air-Conditioning Engineers, Inc., Atlanta, GA (1985).

4. ASTM. Selected ASTM Standards on Packaging, 4th edition, American Society for Testing and Materials, Philadelphia, PA (1994). 